\title{
Sistem Pendukung Keputusan Kenaikan Jabatan Menggunakan Metode Technique for Order Preference by Similarity to Ideal Solution (TOPSIS)
}

\author{
Rahmat Doni' ${ }^{1}$, Faisal Amir ${ }^{2}$, Dicky Juliawan ${ }^{3}$ \\ Universitas Potensi Utama, Medan \\ rahmaddoni113@gmail.com, Faisalamir5pr@gmail.com², dickyjuliawan007@gmail.com³
}

\begin{abstract}
Rumah Bermain Bilal to improve the performance of tutors in educating their students. The problem of leadership in decision-making still uses the choice of methods and assessment processes subjectively so that the process is not in accordance with the goals of the career path. Therefore, it is necessary to make a Technique for Order Preference by Similarity to Ideal Solution (TOPSIS) Method to help make decisions. In this study, using the criteria set by the company, namely planning, learning, evaluation, and training. The ranking results obtained from testing the calculations that the alternative Tutor $F$ is the best tutor with the results of the calculation of 0.804 when compared to the other twelve alternatives. The TOPSIS method has a data accuracy rate of $85 \%$ from thirteen alternatives and can be used as a support for leadership decisions to make recommendations for increasing the career path of tutors.
\end{abstract}

Keywords: Decision Support System (DSS), Promotion, TOPSIS

\begin{abstract}
Abstrak- Jenjang karir merupakan salah satu cara Rumah Bermain Bilal untuk meningkatkan kinerja tutor dalam mendidik siswanya. Permasalahan pimpinan dalam pengambilan keputusan masih menggunakan pemilihan metode dan proses penilaian secara subjektif sehingga prosesnya belum sesuai dengan sasaran jenjang karir. Oleh karena itu, perlu dibuat sebuah Metode Technique for Order Preference by Similarity to Ideal Solution (TOPSIS) dalam membantu membuat keputusan. Pada penelitian ini, menggunakan kriteria yang sudah ditetapkan oleh perusahaan yaitu perencanaan, pembelajaran, evaluasi dan pelatihan. Hasil perankingan yang diperoleh dari pengujian perhitungan bahwa alternatif Tutor F merupakan tutor terbaik dengan hasil perhitungan 0,804 jika dibandingkan dengan kedua belas alternatif lainnya. Metode TOPSIS memiliki tingkat keakurasian data 85\% dari ke tiga belas alternatif dan dapat digunakan sebagai pendukung keputusan pimpinan untuk membuat rekomendasi kenaikan jenjang karier tutor.
\end{abstract}

Kata kunci: Kenaikan Jabatan, TOPSIS, Sistem Pendukung Keputusan (SPK)

\section{PENDAHULUAN}

Kenaikan jenjang karir merupakan tahap dimana suatu perusahaan mengidentifikasikan calon yang sesuai dengan kebutuhan untuk posisi suatu pekerjaan. Meningkatkan taraf kehidupan pada Tutor merupakan tujuan utama dari proses kenaikan jenjang karir Tutor tersebut, dimana etos kerja yang baik serta masa kerja yang mencukupi yang dibutuhkan, sehingga ketika hal tersebut telah dimiliki oleh sebuah perusahaan maka ia akan mampu bertahan di tengah persaingan yang penuh dengan kompetisi dan perubahan. Rumah Bermain Bilal (RBB) adalah instansi yang bergerak dibidang pendidikan dengan jumlah Tutor yang terbatas sehingga akan menyulitkan pimpinan dalam proses kenaikan jenjang karir dari tiap Tutor, karena pimpinan belum tentu mengenal kemampuan 
Tutor secara keseluruhan. Sistem jenjang karir merupakan salah satu cara RBB untuk meningkatkan kinerja Tutor dalam mendidik siswa dan memotivasi Tutor untuk bekerja lebih maksimal dalam upaya memajukan RBB. Hal ini akan menjadi kendala yang cukup signifikan dalam rangka kenaikan jenjang karir dari tiap Tutor, karena hal tersebut harus dilakukan sesuai dengan jenjang dan kemampuan dari tiap-tiap Tutor. Permasalahan yang muncul ketika proses yang dilakukan pimpinan dalam pengambilan keputusan kenaikan jenjang karir, cenderung secara subjektif dan terkadang bertentangan dengan visi dan misi perusahaan. Adapun masalah lain yang terjadi dalam proses kenaikan jenjang karir Tutor yang menjadi cukup kompleks, terutama jika ada Tutor yang memiliki kemampuan dan pertimbangan lain yang tidak jauh berbeda. Dalam kehidupan sehari-hari, setiap manusia dihadapkan dengan masalah pengambilan keputusan yang bermacammacam. Ada keputusan yang mudah diambil, ada keputusan yang baru dapat diambil setelah dipertimbangkan segala macam aspek secara cermat, ada keputusan yang hasilnya hanya membawa konsekuensi bagi pihak tersebut dan ada keputusan yang menyangkut nasib orang banyak. Sedangkan Sistem pendukung keputusan itu sendiri merupakan bagian dari sistem informasi berbasis komputer (termasuk sistem berbasis pengetahuan/manajemen pengetahuan) yang dipakai untuk mendukung pengambilan keputusan dalam suatu organisasi atau perusahaan. Dapat dikatakan sebagai sistem komputer yang mengolah data menjadi informasi dalam pengambilan keputusan masalah semi terstruktur yang spesifik [5].

Salah satu metode yang dapat digunakan untuk Sistem Pendukung Keputusan adalah dengan menggunakan metode Technique For Order Preference By Similarity to Ideal Solution (TOPSIS) [9]. Metode TOPSIS menggunakan konsep dimana alternatif terpilih yang terbaik tidak hanya memiliki jarak terpendek dari solusi ideal positif, namun ada memiliki jarak terpanjang dari solusi ideal negatif. Sistem penunjang keputusan atau SPK yang dikembangkan dengan menggunakan metode TOPSIS dapat membantu dalam mengambil keputusan dalam menentukan karyawan terbaik [6]. Proses kenaikan jabatan harus memiliki kriteria-kriteria yang telah ditentukan oleh RBB diantaranya, Perencanaan, Pembelajaran, Evaluasi dan Pelatihan. Dan alternatif yang digunakan ada tiga belas orang tutor yang berada pada level kuning. Dalam uraian yang telah dikemukakan diatas, penulis mengemukakan lebih lanjut tentang sistem pengolahan data tutor khususnya masalah mengenai kenaikan jabatan yang diajukan dengan judul Sistem Pendukung Keputusan Kenaikan Jabatan Menggunakan Metode TOPSIS.

\section{METODOLOGI PENELITIAN}

Metodologi penelitian ini menggunakan metode TOPSIS (Technique for Order Preference by Similarity to Ideal Solution). TOPSIS merupakan metode pengambilan keputusan multi kriteria menggunakan prinsip bahwa alternatif terpilih harus mempunyai jarak terdekat dari solusi ideal positif dan jarak terpanjang (terjauh) dari solusi ideal negatif untuk menentukan kedekatan relatif dari sudut pandang geometris dengan menggunakan jarak Euclidean (jarak antara dua titik) untuk menentukan kedekatan relatif dari suatu alternatif dengan solusi optimal. Solusi 
ideal positif merupakan jumlah dari seluruh nilai terbaik yang dapat dicapai untuk setiap atribut, sedangkan solusi ideal negatif terdiri dari seluruh.

\subsection{Data}

Pada penelitian ini peneliti mengumpulkan data dan informasi dengan melakukan wawancara dan menyebarkan kuesioner. Data alternatif yang dipergunakan adalah jumlah tutor yang bekerja di Rumah Bermain Bilal (RBB), level yang digunakan untuk kenaikan jenjang karir adalah level kuning dan kriteria penilaian untuk kenaikan jenjang karir adalah Perencanaan, Pembelajaran, Evaluasi dan Pelatihan. Data yang telah didapat nantinya akan diuji mengggunakan metode TOPSIS. Dalam menentukan kenaikan jabatan Tutor yang akan dipilih, diperlukan beberapa kriteria yang digunakan, seperti pada tabel 1.

Tabel 1. Kriteria

\begin{tabular}{|l|l|}
\hline Kriteria & Keterangan \\
\hline K1 & Perencanaan \\
\hline K2 & Pembelajaran \\
\hline K3 & Evaluasi \\
\hline K4 & Pelatihan \\
\hline
\end{tabular}

Alternatif yang akan dijadikan sebagai calon kenaikan jabatan adalah 13 orang Tutor yang berada pada level Kuning. Lihat tabel 2.

Tabel 2. Alternatif

\begin{tabular}{|l|l|}
\hline Alternatif & Keterangan \\
\hline K-A & Tutor A \\
\hline K-B & Tutor B \\
\hline K-C & Tutor C \\
\hline K-D & Tutor D \\
\hline K-E & Tutor E \\
\hline K-F & Tutor F \\
\hline K-G & Tutor G \\
\hline K-H & Tutor H \\
\hline K-I & Tutor I \\
\hline K-J & Tutor J \\
\hline K-K & Tutor K \\
\hline K-L & Tutor L \\
\hline K-M & Tutor M \\
\hline
\end{tabular}

\subsection{Tahapan TOPSIS}

Adapun tahapan dalam menggunakan metode TOPSIS [1]:

a. Membuat matriks keputusan yang ternormalisasi

$$
R_{i j}=\frac{\left[X_{i j}-\operatorname{Min}\left(X_{i j}\right)\right]}{\left[\operatorname{Max}\left(X_{j}\right)-\operatorname{Min}\left(X_{j}\right)\right]}
$$

b. Membuat matriks keputusan ternormalisasi terbobot 


$$
V_{i j}=r_{i j} w_{i j} ; j=1,2,3, \ldots n ; i=1,2,3, \ldots m
$$

c. Menentukan matriks solusi ideal positif dan matriks solusi ideal negative

$$
\begin{aligned}
& \left\{V_{1}^{+}, V_{2}^{+}, V_{3}^{+}, \ldots V_{n}^{+}\right\}\left\{\left(\operatorname{Max}_{i} V_{i j} \mid i=1, \ldots, m\right)\right\} \\
& \left\{V_{1}^{-}, V_{2}^{-}, V_{3}^{-}, \ldots V_{n}^{-}\right\}\left\{\left(\operatorname{Min}_{i} V_{i j} \mid i=1, \ldots, m\right)\right\}
\end{aligned}
$$

d. Menentukan jarak antara setiap nilai alternatif dengan matriks solusi ideal positif dan negatif.

Jarak antara alternatif ke-i dengan solusi ideal positif dirumuskan :

$$
D_{i}^{+}=\left(\sum_{j=1}^{n}\left(V_{i j}-V_{j}^{+}\right)^{2}\right)^{0.5}
$$

Jarak antara alternatif ke-i dengan solusi ideal negatif dirumuskan :

$$
D_{i}^{-}=\left(\sum_{j=1}^{n}\left(V_{i j}-V_{j}^{-}\right)^{2}\right)^{0.5}
$$

e. Menentukan nilai preferensi untuk setiap alternative. Nilai preferensi untuk setiap alternative (Vi) diberikan sebagai berikut :

$$
C_{i}=\frac{D_{i}^{-}}{D_{i}^{-}-D_{i}^{+}} ; i=1,2,3, \ldots m ; 0<C i<1
$$

\section{HASIL DAN PEMBAHASAN}

Berdasarkan hasil analisis yang telah dilakukan, maka tahap selanjutnya dilakukan perhitungan menggunakan metode TOPSIS. Langkah pertama menentukan kriteria dan bobot kriteria. Bobot didapatkan berdasarkan hasil dari wawancara yang dilakukan dengan pimpinan. Dari data yang didapat status kriteria adalah benefit. Langkah selanjutnya menentukan nilai setiap alternative berdasarkan kriteria. Nilai ini didapatkan dari kuesioner yang telah disebarkan. Data alternative tersebut dinormalisasikan dengan perhitungan Normalisasi $\mathrm{R}=$ data nilai/ matrik ternormalisasi. Dapat dilihat pada tabel 3.

Tabel 3. Normalisasi R

\begin{tabular}{|l|r|r|r|r|}
\hline Alternatif & \multicolumn{1}{|c|}{ K1 } & K2 & K3 & K4 \\
\hline Normalisasi & R1 & R2 & R3 & R4 \\
\hline K-A & 0,267165843 & 0,302396753 & 0,250536444 & 0,309540621 \\
\hline K-B & 0,250467977 & 0,235197474 & 0,267238874 & 0,260145841 \\
\hline K-C & 0,300561573 & 0,285596933 & 0,283941303 & 0,263438826 \\
\hline K-D & 0,25380755 & 0,251997294 & 0,287281789 & 0,279903753 \\
\hline K-E & 0,293882427 & 0,262077186 & 0,233834014 & 0,29636868 \\
\hline K-F & 0,260486697 & 0,299036789 & 0,320686648 & 0,312833606 \\
\hline K-G & 0,283863708 & 0,288956897 & 0,317346162 & 0,223923002 \\
\hline K-H & 0,317259438 & 0,30911668 & 0,263898388 & 0,289782709 \\
\hline K-I & 0,290542854 & 0,24863733 & 0,293962761 & 0,256852856 \\
\hline K-J & 0,230430539 & 0,275517041 & 0,257217416 & 0,276610768 \\
\hline K-K & 0,317259438 & 0,30911668 & 0,263898388 & 0,289782709 \\
\hline
\end{tabular}




\begin{tabular}{|l|c|c|c|c|}
\hline Alternatif & K1 & K2 & K3 & K4 \\
\hline Normalisasi & R1 & R2 & R3 & R4 \\
\hline K-L & 0,290542854 & 0,24863733 & 0,293962761 & 0,256852856 \\
\hline K-M & 0,230430539 & 0,275517041 & 0,257217416 & 0,276610768 \\
\hline
\end{tabular}

Langkah selanjutnya menentukan matrik solusi ideal positif dan negatif. Nilai positif adalah nilai Max dari hasil nilai kriteria terbobot, sedangkan nilai negatif adalah nilai Min dari hasil nilai kriteria terbobot. Hasil dapat dilihat pada tabel 4.

Tabel 4. Matrik Solusi Ideal Positif dan Negatif

\begin{tabular}{|l|l|l|l|}
\hline POSITIF & A+ & NEGATIF & A- \\
\hline Y1+ & 0,063451888 & Y1- & 0,046086108 \\
\hline Y2+ & 0,061823336 & Y2- & 0,047039495 \\
\hline Y3+ & 0,032068665 & Y3- & 0,023383401 \\
\hline Y4+ & 0,156416803 & Y4- & 0,111961501 \\
\hline
\end{tabular}

Pada tabel 5 dapat dilhat jarak antara setiap alternative dengan matriks solusi ideal positif dan matriks solusi ideal negatif. Nilai positif adalah hasil akar dari hasil A+ dikurangi data terbobot pangkat 2, sedangkan nilai negative adalah hasil pangkat dari A- dikurangi data terbobot dipangkat 2.

Tabel 5. Jarak Alternatif Dengan Matriks Solusi Ideal Positif dan Solusi Ideal Negatif

\begin{tabular}{|c|c|r|r|}
\hline Jarak Alternatif & Positif(+) & \multicolumn{1}{|c|}{ Negatif(-) } & \multicolumn{1}{|c|}{$\mathbf{D}^{+}+\mathbf{D}^{-}$} \\
\hline K-A & 0,012413802 & 0,045497174 & 0,057910976 \\
\hline K-B & 0,033460017 & 0,018847873 & 0,05230789 \\
\hline K-C & 0,025627001 & 0,026717432 & 0,052344433 \\
\hline K-D & 0,023954192 & 0,029071919 & 0,053026111 \\
\hline K-E & 0,015924045 & 0,038756167 & 0,054680212 \\
\hline K-F & 0,011532126 & 0,047443239 & 0,058975365 \\
\hline K-G & 0,045135941 & 0,017307511 & 0,062443452 \\
\hline K-H & 0,012848542 & 0,04016897 & 0,053017512 \\
\hline K-I & 0,031071915 & 0,021424595 & 0,05249651 \\
\hline K-J & 0,026740132 & 0,027649497 & 0,054389629 \\
\hline K-K & 0,012848542 & 0,04016897 & 0,053017512 \\
\hline K-L & 0,031071915 & 0,021424595 & 0,05249651 \\
\hline K-M & 0,026740132 & 0,027649497 & 0,054389629 \\
\hline
\end{tabular}

Langkah terakhir menentukan nilai preferensi dari setiap kriteria dimana hasil akhir adalah solusi ideal negatif dibagi dengan jumlah solusi ideal positif dan negatif.

Tabel 6. Nilai preferensi Vi

\begin{tabular}{|c|c|c|c|}
\hline No & Nama & Alternatif & V \\
\hline $\mathbf{1}$ & Tutor F & K-F & 0,804458586 \\
\hline $\mathbf{2}$ & Tutor A & K-A & 0,785639913 \\
\hline $\mathbf{3}$ & Tutor K & K-K & 0,757654755 \\
\hline $\mathbf{4}$ & Tutor H & K-H & 0,757654755 \\
\hline $\mathbf{5}$ & Tutor E & K-E & 0,708778655 \\
\hline $\mathbf{6}$ & Tutor D & K-D & 0,548256674 \\
\hline
\end{tabular}




\begin{tabular}{|c|l|c|c|}
\hline No & Nama & Alternatif & V \\
\hline $\mathbf{7}$ & Tutor C & K-C & 0,510415926 \\
\hline $\mathbf{8}$ & Tutor M & K-M & 0,508359724 \\
\hline $\mathbf{9}$ & Tutor J & K-J & 0,508359724 \\
\hline $\mathbf{1 0}$ & Tutor L & K-L & 0,408114657 \\
\hline $\mathbf{1 1}$ & Tutor I & K-I & 0,408114657 \\
\hline $\mathbf{1 2}$ & Tutor B & K-B & 0,360325622 \\
\hline $\mathbf{1 3}$ & Tutor G & K-G & 0,277170958 \\
\hline
\end{tabular}

Nilai terbesar pada tabel 6 ada pada tutor F sehingga alternatif K-F adalah alternatif yang terpilih sebagai alternatif terbaik. Dengan kata lain, tutor $\mathrm{F}$ akan terpilih sebagai tutor ranking pertama atau tutor yang terpilih untuk naik jabatan ke level yang lebih tinggi.

\section{KESIMPULAN}

Sistem Pendukung Keputusan menggunakan Metode Technique for Order Preference by Similarity to Ideal Solution (TOPSIS) pada penelitian ini digunakan sebagai alat bantu pengambilan keputusan untuk kenaikan jenjang karier Tutor Rumah Bermain Bilal. Penerapan metode TOPSIS dapat memberikan keputusan yang tepat dalam menentukan kenaikan Jabatan Tutor dengan kriteria yang sudah ditetapkan yaitu Perencanaan, Pembelajaran, Evaluasi dan Pelatihan. Hasil perankingan yang diperoleh dari pengujian perhitungan bahwa alternatif Tutor $\mathrm{F}$ merupakan Tutor terbaik dengan hasil perhitungan 0,804 jika dibandingkan dengan kedua belas alternatif lainnya. Metode TOPSIS memiliki tingkat keakurasian data 85\% dari tiga belas alternatif dan dapat digunakan sebagai pendukung keputusan pimpinan untuk membuat rekomendasi kenaikan Jabatan Tutor.

\section{DAFTAR PUSTAKA}

[1] Vickky Listyaningsih dan Ema Utami, "Decision Support System Performance-Based Evaluation of Village Government Using AHP and TOPSIS Methods : Secang Sub-disctrict of Magelang Regency as a Case Study", L.J Intelligent Systems and Applications, 18-28, April 2018.

[2] Titin Prihatin, "Perbandingan Metode TOPSIS dan SAW Dalam Penentuan Tutor Berprestasi", Jurnal Teknik Komputer AMIK BSI, Vol. 5, No. 1, Februari 2019.

[3] Rahmi Yuniarti, Wifqi Azlia dan Umroh Fitriana, "Analisis kelayakan Investasi Penambahan Truk Pada Distributor Semen Dengan Metode AHP dan TOPSIS”, Jurnal Ilmiah Teknik Industri, Vol.17(1), Hal. 46-55, Juni 2018.

[4] Achmad Azhar Azhari, Yusni Nyura dan Abdul Najib, "Perbandingan Metode SAW dan TOPSIS Pada Penerimaan Siswa Praktek Kerja Lapangan", Prosiding Seminar Nasional Ilmu Komputer dan Teknologi Informasi, Vol. 3, No. 1, Maret 2018.

[5] Rahel Adelina Hutasoit, Sulikhun dan Anjar Wanto, "Analisa Pemilihan Barista Dengan Menggunakan Metode TOPSIS (Studi Kasus : Mo Caffee)”, Konfrensi Nasional Teknologi Informasi dan Komputer, Vol. 2, No. 1, Oktober 2018.

[6] Hylenarti Hertyana, "Sistem Pendukung Keputusan Penentuan Karyawan Terbaik Menggunakan Metode TOPSIS", Jurnal Ilmu Pengetahuan dan Teknologi Komputer, Vol. 4, No. 1, Agustus 2018.

[7] Suyanti dan Rusdianto Roestam, “Analisis Perbandingan Metode Simple Additive Weighting (SAW) Dan TOPSIS Dalam Pemilihan Tutor Teladan Pada SMA Negeri 4 Sarolangun”, Jurnal Managemen Sistem Informasi, Vol. 3, No. 3, September 2018. 
[8] Khoirun Nisa, Kusrini dan Sudarmawan, "Sistem Pendukung Keputusan Kenaikan Pangkat Karyawan", Jurnal INFORMA Politeknik, Indonusa, Surakarta, Vol. 4 No. 3, 2018.

[9] Yani Maulita dan Relita Buaton, "Perbandingan Hasil Penggunaan Metode WP Dan TOPSIS Pada Sistem Pendukung Keputusan Pemilihan Lokasi Lahan Tambak Paling TErbaik Untuk Dijadikan Usaha Tambak Air Payau", Jurnal METHODIKA, Vol. 2, No. 2, Nopember 2016. 